\title{
Strain accumulation in South Korea inferred from GPS measurements
}

\author{
Shuanggen Jin ${ }^{1,2}$ and Pil-Ho Park ${ }^{1}$ \\ ${ }^{1}$ Space Geodesy Research Group, Korea Astronomy and Space Science Institute, Daejeon 305-348, Korea \\ ${ }^{2}$ Shanghai Astronomical Observatory, Chinese Academy of Sciences, Shanghai 200030, China
}

(Received September 22, 2005; Revised January 4, 2006; Accepted January 10, 2006; Online published May 12, 2006)

\begin{abstract}
Monitoring the variation of the crustal strain is a key issue to understand the physical process of crustal tectonic activities. In this paper, GPS data for the period from March 2000 to February 2004 were analyzed to quantitatively investigate the plate deformation patterns and distributions in the South Korean peninsula. The results show two anomalous rates of strain accumulation in South Korea, a W-E compression accumulation of crustal strain in the East and West parts, and a N-S extension strain accumulation in the middle part along the longitude of about $127.5^{\circ} \mathrm{E}$. In addition, the GPS-derived seismic moment accumulation rate is significant and consistent with recent historic earthquakes and fault zones in South Korea. The most anomalous seismic moment rates are in the middle part (about $127.3^{\circ} \mathrm{E}, 35.5^{\circ} \mathrm{N}$ ), North edge (about $128.0^{\circ} \mathrm{E}, 38.0^{\circ} \mathrm{N}$ ) and Northeast part (about $128.5^{\circ} \mathrm{E}, 37.3^{\circ} \mathrm{N}$ ) of South Korea, indicating a high earthquake risk.
\end{abstract}

Key words: GPS, South Korea, strain accumulation.

\section{Introduction}

The Korean peninsula is located in the northeastern Asia margin, a convergent region of Chinese continent and the Japanese Island Arc, which is characterized by the subduction of the Philippine Sea plate and the Southeastward expulsion of Eurasian plate (Molnar and Tapponnier, 1975; Zonenshain and Savostin, 1981; Kato et al., 1998a; Kogan et al., 2000, Jin and Zhu, 2003). And the physical process caused by tectonic activities is complex. Accurate measurements of deformation pattern in the Korean peninsula will contribute to understand tectonic features and evolution of the deformation belts in northeastern Asia. Now the permanent Korea GPS Network (KGN), with an average $50 \mathrm{~km}$ spatial interval of GPS sites, gives us the ability to obtain precise geodetic measurements with dense spatial sampling. Hamdy et al. (2005) initially analyzed the horizontal deformation of South Korea using 3-year GPS data, but didn't show the high-resolution deformation pattern and strain accumulation. However, the significant strain accumulation caused by the tectonic activities (such as earthquakes) will provide an essential constraint on the physical processing of earthquakes (Sagiya et al., 2002). Therefore, monitoring the spatial variation of the strain and comprehensive understanding of strain accumulation pattern are beneficial to reveal the physical process of crustal tectonic activities and to evaluate the earthquake risk. In this paper, we are to quantitatively investigate the plate deformation pattern and distribution of dilation strain rates in South Korea using 4-year continuous GPS observations (2000-2004), and attempt to determine whether there are regions with anomalous strain rates within South Korea, and if so, whether they

Copyright (c) The Society of Geomagnetism and Earth, Planetary and Space Sciences (SGEPSS); The Seismological Society of Japan; The Volcanological Society of Japan; The Geodetic Society of Japan; The Japanese Society for Planetary Sciences; TERRAPUB correspond to seismic area.

\section{Data Processing and Analysis}

To examine crustal motion on Korean peninsula more completely and to determine tectonic characteristics clearly, a permanent Korean GPS Network (KGN) (see Fig. 1) was established in 2000. The continuous GPS observations provide important data to investigate crustal deformation in the South Korean Peninsula, which will contribute to the reconstruction of the past crustal movements and understanding the tectonics in the South Korean peninsula.

We analyzed all available data for the period from March 2000 to February 2004 using GAMIT software (King and Bock, 1999) with IGS precise orbits and IGS Earth Rotation Parameters. All loosely constrained solutions for each day are then combined using the GLOBK, and the reference frame is applied to the solution by performing a seven-parameter transformation to align it to ITRF2000 with global 54 core stations (Altamimi et al., 2002). The site velocities are estimated by least square linear fitting to time variation of the daily coordinates for each station. And the velocity uncertainties are estimated using a method by Mao et al. (1999), which considers white noise, flicker noise and random walk noise in the error estimates. The 1 -sigma quality of each station is $0.7-0.9 \mathrm{~mm} / \mathrm{yr}$ for $\mathrm{NS}$ component and 0.3-1.9 mm/yr for EW-component as well as $1.1-2.4 \mathrm{~mm} / \mathrm{yr}$ for vertical component. All station velocities are referred to the stable Amurian plate through the following equation:

$$
V_{\text {deformation rate }}=V_{\mathrm{GPS} \text { observed }}-\left(\Omega_{\mathrm{AM} / \mathrm{EU}}+\Omega_{\mathrm{EU}}\right) \times r
$$

where $\Omega_{\mathrm{AM} / \mathrm{EU}}$ is the Euler's vector of Amurian plate (AM) with respect to the Eurasian plate (EU) determined by Heki et al. (1999), $\Omega_{\mathrm{EU}}$ is the Euler's vector of EU plate in ITRF2000 obtained by Altamimi et al. (2002), and $r$ is the 


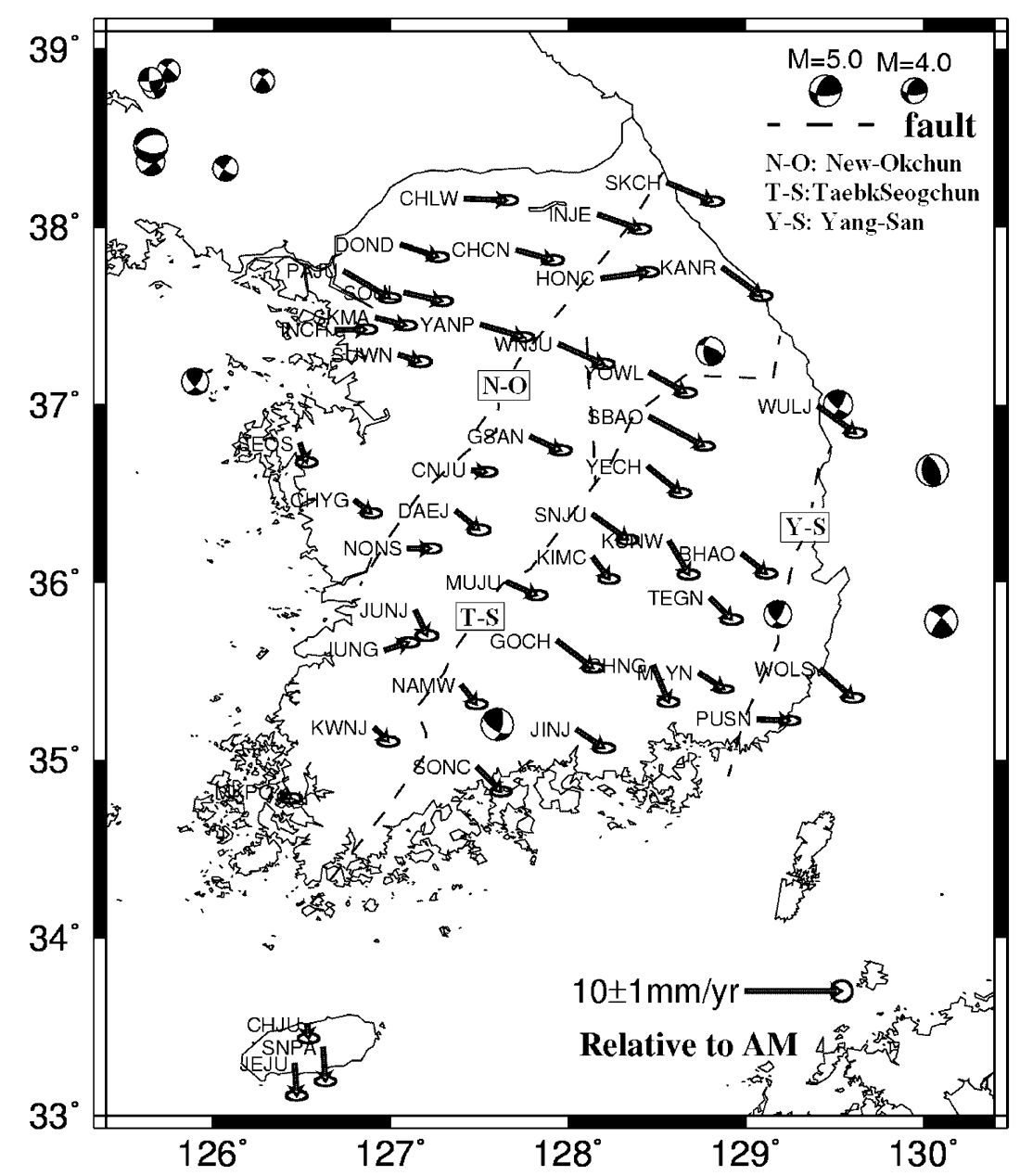

Fig. 1. The velocity field derived from 4-year GPS observations in the Amurian plate (AM) fixed reference frame, fault lines and epicentral distribution and fault plane solutions (lower-hemisphere equal-area projection) for major 14 events with $M_{w} \geq 4.0$ in and around the Korean Peninsula from 1936-2004. Solid and open quadrants denote the extension and compression, respectively. Error ellipses are $95 \%$ confidence limits.

position vector of GPS sites. And thus the GPS deformation velocity field in the AM fixed reference frame can be obtained (Fig. 1).

Some results are summarized as follows: (1) the sites in Korea are moving Southeast with velocities of $1 \mathrm{~mm} / \mathrm{yr}-5$ $\mathrm{mm} / \mathrm{yr}$ relative to the Amurian plate; and (2) the deformation rates of all sites are almost closer with each other. It indicates that the South Korean peninsula is approximately rigid and lies on the stable region. In addition, our relative velocity field is almost the same as Hamdy et al. (2005), but has an improvement because we used longer GPS observations (4 years) and more sophisticated processing strategies (e.g. ITRF2000 alignment).

\section{Results and Discussion}

In order to further understand the deformation pattern and process within the Korea crust, monitoring the variation of the crustal strain is a key issue. The dense array of the continuous KGN provides an important kinematic velocity field to determine the crustal strain in the South Korean peninsula. Under the hypothesis that the velocity field varies linearly inside each small sub-network covering the GPS sites, we can calculate the average horizontal velocity gradient over each subnetwork. Because the velocity gra- dient generally incorporates both deformation and rotation, this 2-D tensor is asymmetric. The $\mathrm{g}$ can be separated into a symmetric and anti-symmetric part as follows (Malvern, 1969):

$$
g=\frac{1}{2}\left(g+g^{T}\right)+\frac{1}{2}\left(g-g^{T}\right)
$$

It's symmetric part is the strain rate tensor $\left(\dot{\varepsilon}_{1}, \dot{\varepsilon}_{2}\right)$ while it's anti-symmetric part gives a local measurement of the rate of rigid rotation.

In order to reduce the effects of abnormal site motion, the subnetwork with four sites is used to estimate the strain parameters. We divide the South Korean peninsula into 32 small quadrangle subnetworks where the obvious anomalous site PNJU is excluded at the Northwest edge and use the horizontal velocity field of the $\mathrm{KGN}$ in the Amurian plate fixed reference frame to estimate the strain parameters of each subnetwork. The strain rates calculated from the horizontal velocity field are shown in terms of their principle axes in Fig. 2, where the uncertainty of strain rates ranges from $0.3 \times 10^{-8} / \mathrm{yr}$ to $2.1 \times 10^{-8} / \mathrm{yr}$. The magnitude and distribution variation of strain rates are wholly small with an order of $10^{-8} / \mathrm{yr}$, which is one order of magnitude smaller when compared with strain rates of about $10^{-7} / \mathrm{yr}$ in areas of high crustal activity in Japan (Kato et al., 1998b; 


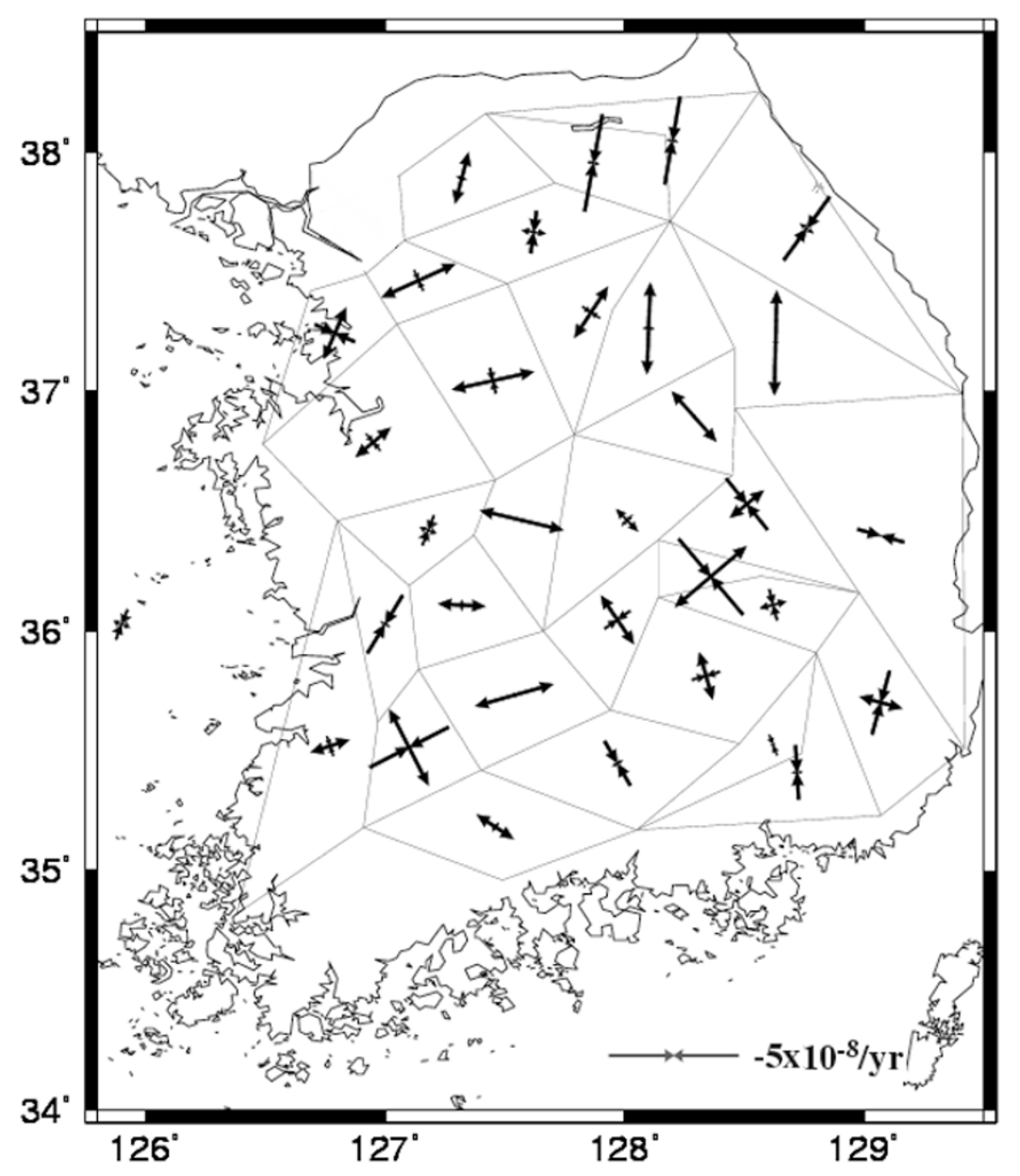

Fig. 2. Principal horizontal axes of the strain rate tensor in South Korea obtained from the GPS velocity field. The convergent arrows are contraction and the divergent arrows are extension.

EL-Fiky, 2000), according with lower and less earthquake activities within recent one century in South Korea (Kim and Lee, 2000). The Fig. 3 shows the dilation rate in unit of $10^{-8} / \mathrm{yr}$, where the positive value denotes the extension and the negative value represents the compression. It is clearly seen that the positive dilation locates at the center of South Korea and the negative dilation locates West and East part of South Korea. Meanwhile we further estimate the whole principal strain rate of South Korea (in Fig. 4) with all GPS data, according with Hamdy et al. (2005). It has indicated that South Korea is under both of W-E compressional and $\mathrm{N}-\mathrm{S}$ extensional strain regimes. In addition, we interpolate the velocity field in each $0.5^{\circ} \times 0.5^{\circ}$ grid using the velocity field in Fig. 1 with a Green's function approach, Splines in Tension ( $\tau=0.95$ ) (Wessel and Bercovici, 1998), and further estimate the strain rates of each grid quadrangle network. Comparing with the GPS directly derived strain pattern and distribution, it shows a good agreement.

Figure 1 lists the epicentral distribution and fault plane solutions (lower-hemisphere equal-area projection) for major 14 events with $M_{w} \geq 4.0$ in and around the Korean Peninsula from 1936-2004. Solid and open quadrants denote the extension and compression, respectively. And the lower-hemisphere equal-area projection of the $\mathrm{P}$ (open circle) and $\mathrm{T}$ (solid circle) axes for 14 events is plotted in Fig. 5, which shows that the average $\mathrm{P}$ - and $\mathrm{T}$-axes were
ENE-WSW and NNW-SSE direction, respectively. Compared with the geodetic results, we find that the average strain pattern is almost consistent with the earthquake source mechanism. The compression rates in the W-E direction are maybe caused by the eastward expulsion due to the collision of India with Eurasia and the western extrusion with the SW Japanese Island Arc, and thus, the W-E extrusion maybe leads to extension of the South Korean peninsula in the N-S direction. This speculation should be further investigated and testified in the future.

In addition, the estimated strain rates in South Korea will contribute to understand the intensity of tectonic activities and crustal anomalous features as well as the evaluation of earthquake risk. To investigate in more detail non-uniform strain accumulation and the potential earthquake risk in South Korea, the calculated principal strain rates are transformed to a seismic moment accumulation rate map. Given that the crustal strain accumulation is taken up seismically, the scalar seismic moment release rate can be determined based on the formula (Savage and Simpson, 1997):

$$
\dot{M}_{0}=2 \mu A H_{s} \max \left(\left|\dot{\varepsilon}_{1}\right|,\left|\dot{\varepsilon}_{2}\right|,\left|\dot{\varepsilon}_{1}+\dot{\varepsilon}_{2}\right|\right)
$$

where $\dot{M}_{0}$ is the seismic moment accumulation rate, $\mu$ is the elastic layer rigidity, $H_{s}$ is the seismogenic depth, $A$ is the area of the concerned region (here is the area of each $0.5^{\circ} \times 0.5^{\circ}$ grid network), $\dot{\varepsilon}_{1}$ and $\dot{\varepsilon}_{2}$ are the principal sur- 


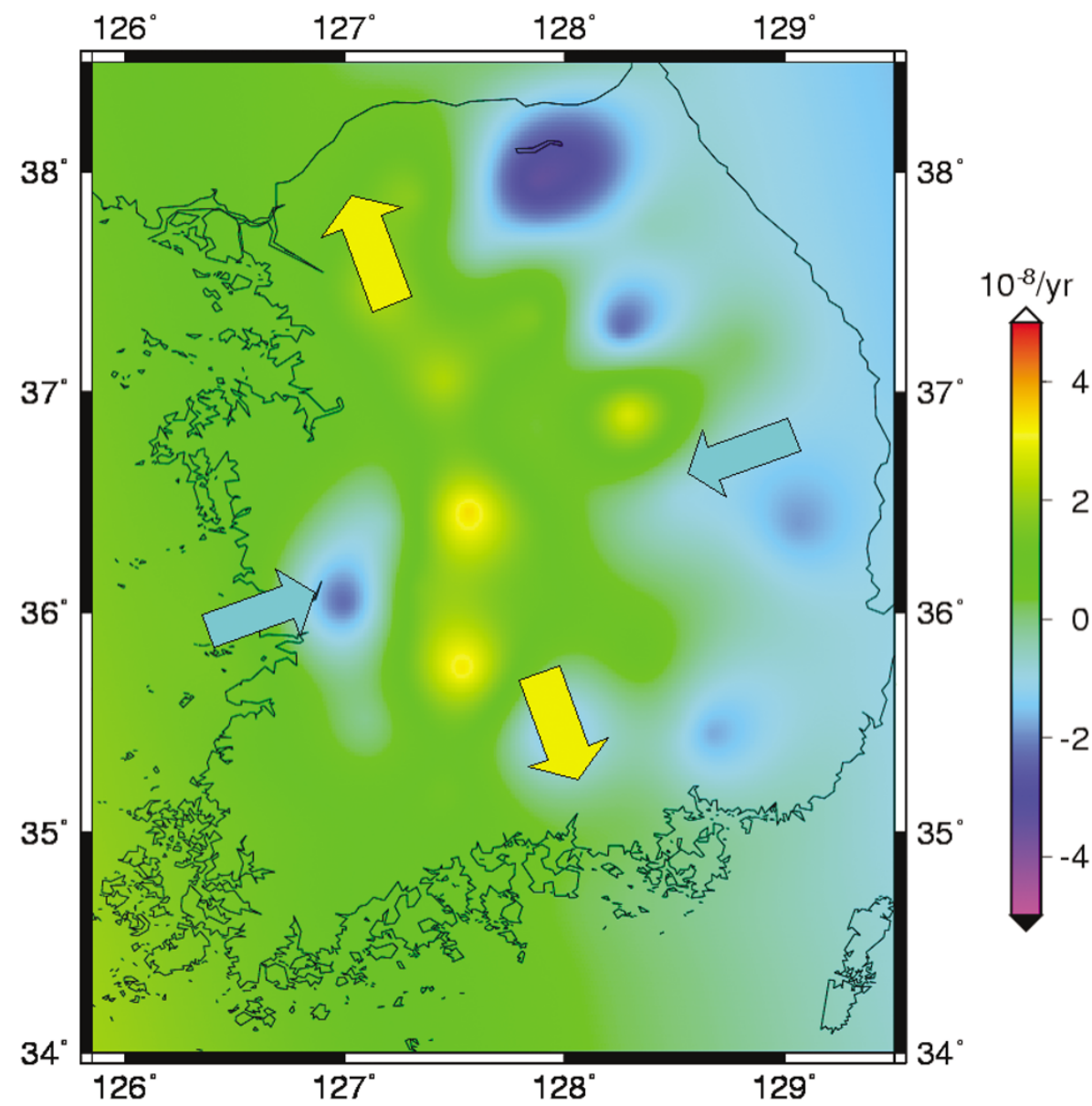

Fig. 3. Contour map dilation rates in South Korea. The positive value denotes the extension and the negative value represents the compression.

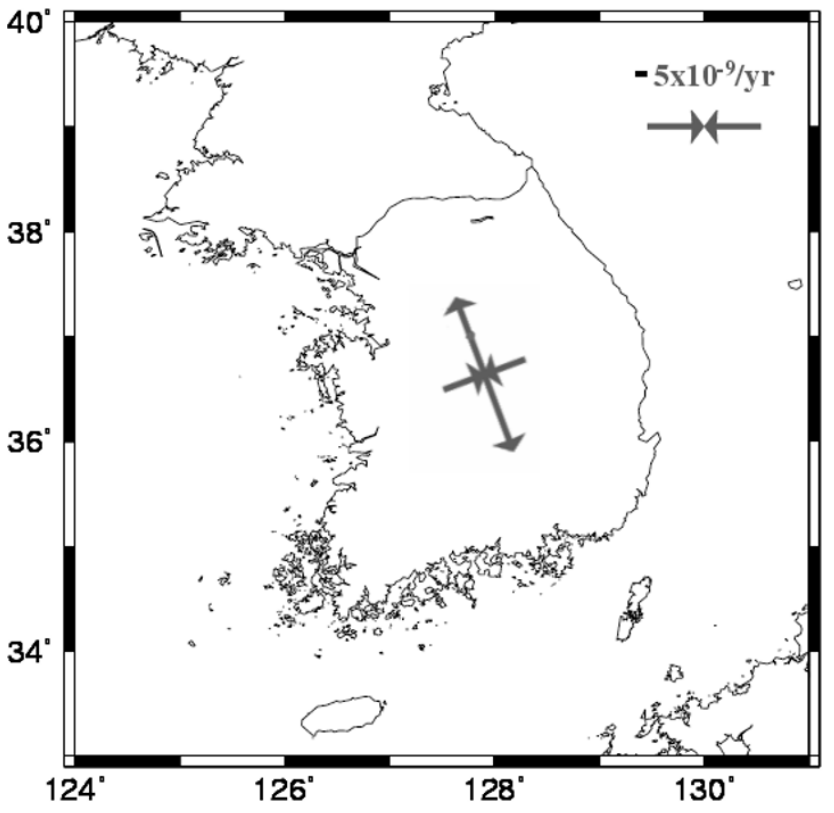

Fig. 4. The total principal strain rate in South Korea.

face extensions and contraction rates. In this note, $H_{s}$ is assumed a usual depth of $10 \mathrm{~km}$ and $\mu$ adopts a standard value of the shear modulus $3 \times 10^{10} \mathrm{Nm}^{-1}$ (Hanks and Kanamori, 1979). And thus the seismic moment rate is ob-

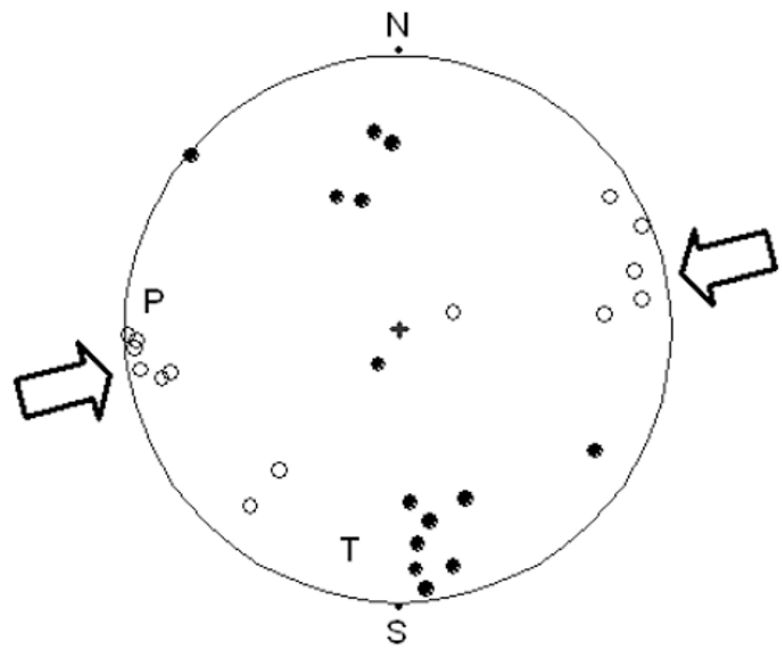

Fig. 5. Lower-hemisphere equal-area projection of the $\mathrm{P}$ (open circle) and $\mathrm{T}$ (solid circle) axes for 14 events in and around South Korea from 1936 to 2004 .

tained showing in Fig. 6. The mean uncertainty is about $0.4 \times 10^{16} \mathrm{Nm} \mathrm{yr}^{-1}$. There are three outstanding subregions in South Korea: one is North margin (marked "A" at about $128.0^{\circ} \mathrm{E}, 38.0^{\circ} \mathrm{N}$ ) with values as large as $2.3 \times 10^{16} \mathrm{Nm}$ $\mathrm{yr}^{-1}$; another is the northeastern part (marked " $\mathrm{B}$ " at about $128.5^{\circ} \mathrm{E}, 37.3^{\circ} \mathrm{N}$ ) with a value of $3.0 \times 10^{16} \mathrm{Nm} \mathrm{yr}^{-1}$, just 


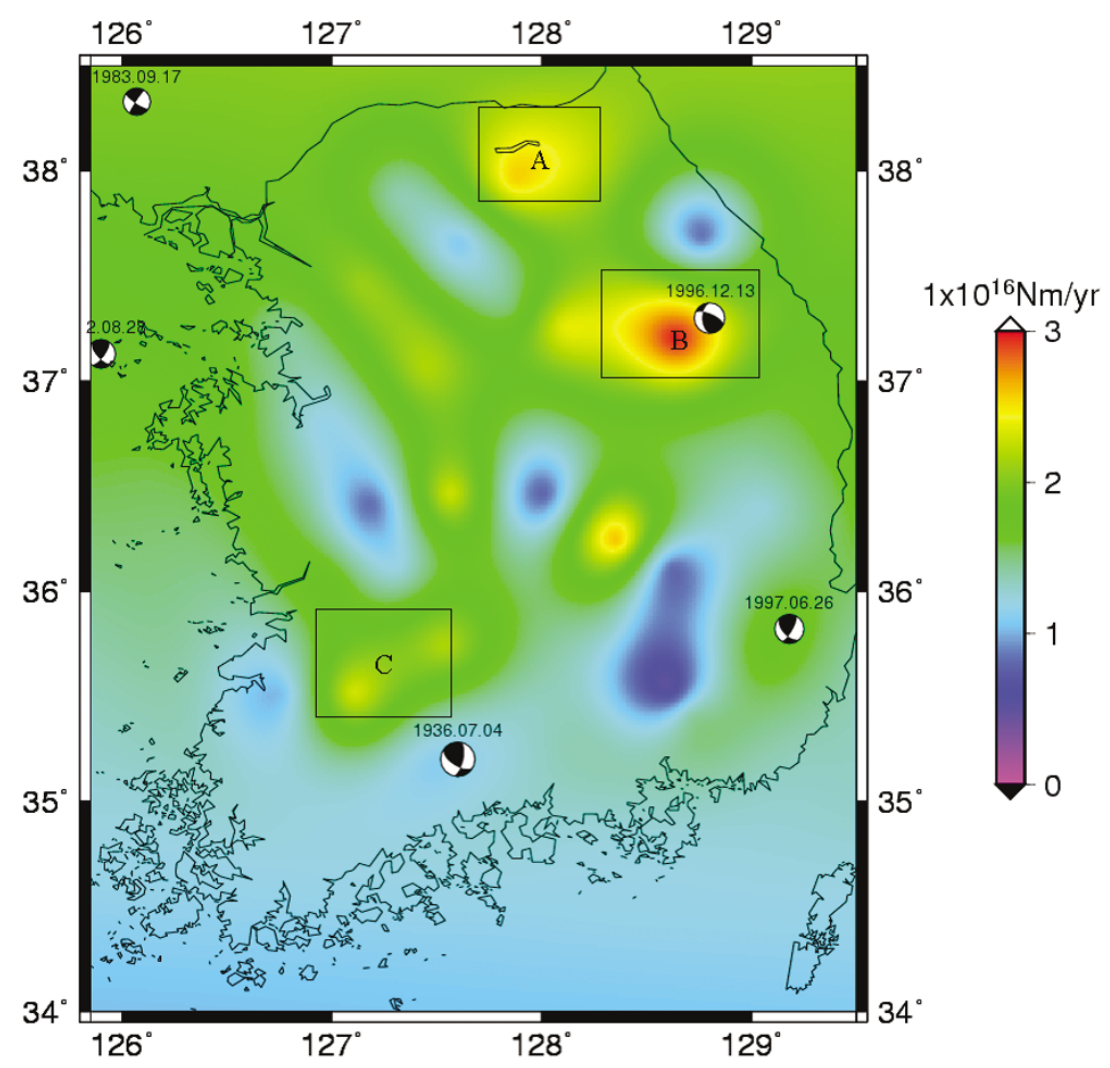

Fig. 6. Contour map of the seismic moment accumulation rate and historic earthquakes $\left(M_{w} \geq 4.0\right)$ from 1936 to 2004 in South Korea.

located near the epicenter of the earthquake on December $13,1996\left(M_{w}=4.8\right)$, and the last anomalous region is the middle part (marked "C" at about $127.3^{\circ} \mathrm{E}, 35.5^{\circ} \mathrm{N}$ ) with a value up to $2.2 \times 10^{16} \mathrm{Nm} \mathrm{yr}^{-1}$, near the bigger earthquake $\left(M_{w}=5.1\right)$ on July 4, 1936 on inland of the South Korean peninsula within the recent 100 years. These regions with a high seismic moment rate are also located near fault zones (seeing Fig. 1). According to the available seismic information, these regions are actually relatively active seismic areas in South Korea with average 20 earthquake events per year since 1978 and their magnitudes are ranging from 2.0 to 4.0 on Richter scale (Korea Meteorological Administration, 2001). If the bigger moment accumulation rate in the middle Korea with $2.2 \times 10^{16} \mathrm{Nm} \mathrm{yr}^{-1}$ will be released by earthquake $\left(M_{w}=6.0\right)$ in South Korea, it at least requires 57 years.

\section{Concluding Remarks}

The current kinematics of crustal motions in South Korea is analyzed in term of strain rates based on four years of continuous GPS observations (2000-2004). The strain rates are the order of $10^{-8} / \mathrm{yr}$, which is a good agreement with low recent crustal activities in the South Korean peninsula. The dilation strain field distribution clearly shows the present-day deformation type and intensity in South Korea. An obvious EW compression accumulation of crustal strain exists in the East and West parts of South Korea, and a NS extension strain accumulation mainly dominates the middle part along the longitude $127.5^{\circ} \mathrm{E}$ in South Korea. The average GPS strain pattern coincides with the earthquake source mechanism. In addition, the GPS-derived seismic moment rates show that significant anomalous seismic moment rates are in North margin (about $128.0^{\circ} \mathrm{E}, 38.0^{\circ} \mathrm{N}$ ), Northeast part (about $128.5^{\circ} \mathrm{E}, 37.3^{\circ} \mathrm{N}$ ) and the middle part (about $127.3^{\circ} \mathrm{E}, 35.5^{\circ} \mathrm{N}$ ) of South Korea, respectively, which are fault zones and most seismic areas in South Korea. Therefore, the geodetic strain accumulation estimates demonstrate a challenge to attempt to evaluate the earthquake risk. In addition, the regions with high anomalous seismic moment rates maybe indicate a high earthquake risk in the future. However, some seismic moment accumulation estimations may not be real due to some anomalous GPS station motions, such as the landslide, environment variations, etc. Therefore, this motion accumulation and speculations need to further investigate with closer analysis using more available data (longer and denser GPS observations and InSAR data). These densified and more stable geodetic data will enable the classification of the strain changes in South Korea.

Acknowledgments. All figures were made with the public domain software GMT (Wessel and Smith, 1998). We are grateful to National Geographic Information Institute (NGII), Ministry of Government Administration and Home Affairs (MOGAHA) and other members who made the observation data available. We also thank Dr. Kosuke Heki, Dr. S. Miyazaki and Dr. Takuya Nishimura for useful comments and improvements on the manuscript. This work was supported by the Korean Ministry of Science and Technology under grants M2-0306-01-0004, M6-0404-00-0018 and M6-0404-00-0010.

\section{References}

Altamimi, Z., P. Sillard, and C. Boucher, ITRF2000: A new release of the International Terrestrial Reference Frame for Earth science applications, 
J. Geophys. Res., 107(B10), 2214, doi: 10.1029/2001JB000561, 2002.

EL-Fiky, S. G., Elastic and inelastic strains in the Japanese Islands deduced from GPS dense array, Earth Planets Space, 52, 1107-1112, 2000.

Hamdy, A. M., P.-H. Park, and H. C. Lim, Horizontal deformation in South Korea from permanent GPS network data, 2000-2003, Earth Planets Space, 57, 77-82, 2005.

Hanks, T. C. and H. Kanamori, A moment-magnitude scale, J. Geophys. Res., 84, 2348-2350, 1979.

Heki, K., S. Miyazaki, H. Takahashi, M. Kasahara, F. Kimata, S. Miura, and K. An, The Amurian plate motion and current plate kinematics in East Asia, J. Geophys. Res., 104, 29147-29155, 1999.

Jin, S. G. and W. Y. Zhu, Active Motion of Tectonic Blocks in Eastern Asia: Evidence from GPS Measurements, ACTA Geological Sinica-English Edition, 77(1), 59-63, 2003.

Kato, T., Y. Kotake, S. Nakao, J. Beavan, K. Hirahara, M. Okada, M. Hoshiba, O. Kamigaichi, M. L. Kaiser, M. D. Desch, K. Goetz, J.-L. Bougeret, and R. Manning, Initial results from WING, the continuous GPS network in the western Pacific area, Geophys. Res. Lett., 125(3), 369-372, 1998a.

Kato, T., G. S. El-Fiky, E. N. Oware, and S. Miyazaki, Crustal strains in the Japanese islands as deduced from dense GPS array, Geophys. Res. Lett., 25(18), 3445-3448, 1998b.

Kim, S. G. and K. S. Lee, Seismic risk map of Korea obtained by using South and North Korea Earthquake catalogues, J. of Earthquake Engineering Society of Korea, 4(1), 13-34, 2000.

King, R. W. and Y. Bock, Documentation for the GAMIT GPS Analysis Software, Mass. Inst. of Technol., Cambridge Mass, 1999.

Kogan, M. G., G. M. Steblov, R. W. King, T. A. Herring, D. L. Frolov,
S. G. Egorov, V. Y. Levin, and A. Jones, Geodetic constrains on the rigidity and relative motion of Eurasian and North American, Geophys. Res. Lett., 27, 2041-2044, 2000.

Korea Meteorological Administration. Earthquake observation report 1978-2000, Korea Meteorological Administration Seoul, Korea, p. 166, 2001.

Malvern, L. E., Introduction to the mechanics of a continuum medium, Prentice-Hall, Englewood Cliffs, NJ, 1969.

Mao, A., C. G. A. Harrison, and T. H. Dixon, Noise in GPS coordinate time series, J. Geophys. Res., 104(B2), 2797-2816, 1999.

Molnar, P. and P. Tapponnier, Cenozoic tectonic of Asia: effects of a continental collision, Science, 189, 419-426, 1975.

Sagiya, T., T. Nishimura, Y. Iio, and T. Tada, Crustal deformation around the northern and central Itoigawa-Shizuoka, Earth Planets Space, 54, 1059-1063, 2002.

Savage, J. C. and R. W. Simpson, Surface strain accumulation and the seismic moment tensor, Bulletin Seismic Society of America, 87, 13451353, 1997.

Wessel, P. and D. Bercovici, Interpolation with Splines in Tension: A Green's Function Approach, Mathematical Geology, 30, 77-93, 1998.

Wessel, P. and W. H. F. Smith, New, improved version of Generic Mapping Tools released, Eos, Trans. Amer. Geophys. Union, 79, 579, 1998.

Zonenshain, L. P. and L. A. Savostin, Geodynamics of the Baikal rift zone and plate tectonics of Asia, Tectonophysics, 76, 1-4, 1981.

S. Jin (e-mail: sgjin@kasi.re.kr) and P. Park 